\title{
Language Factors Influencing Chinese College Students' English Learning Attitude Towards E-learning
}

\author{
Ze Liu ${ }^{1}{ }^{*}$, Nianci Ren ${ }^{2}$, Hangyuan Dong ${ }^{1}$, Yidan Zhu ${ }^{1}$, Wen $\mathrm{Xu}^{1,3}$, \\ Jiamin Tian ${ }^{1}$, Yan Zhao ${ }^{1}$
}

\author{
${ }^{1}$ Faculty of Education, Xi'an SiYuan University, No. 28 Shui An Road, Xi'an, Shaanxi, China \\ ${ }^{2}$ School of Foreign Languages and Literature, Beijing Normal University, Beijing, China \\ ${ }^{3}$ National Institute of Development Administration, Bangkok, Thailand \\ *Corresponding author. Email: liuze_xauat@126.com
}

\begin{abstract}
The recent rapid development of internet technology in China has popularized English E-learning among Chinese college students. This article aims to explore diverse user attitudes towards E-learning platforms between two groups of Chinese college students enrolled in English and Putonghua as the Medium of Instruction programs, respectively. The results reveal that students with different language backgrounds (English and Putonghua) exhibit different motivations for E-learning services: Positive Feedback (PF) connects Learning Motivation (LM) and Using Attitude (UA) for students with an English language background; in contrast, Sharing at Social Network (SSN) serves as the bridge between Environmental Impact (EI) and Using Attitude (UA) for students in the other group.
\end{abstract}

Keywords: E-learning, English learning, Chinese college students

\section{INTRODUCTION}

Moodle, Technology Entertainment Design (TED), Open Learning, and other online learning platforms have rapidly grown in popularity among young adults worldwide for reasons such as daily learning and examination preparation. This new mode develops swiftly in both developed and developing countries and is extensively welcomed by young people, especially college students [1]. Technological development leads to an increase in the unity of web teaching courses and, accordingly, a unity in English language learning[2], as E-learning enhances the engagement, attendance, and motivation of students and provides teachers and students with creative and practical ideas [3]. A vast number of universities in China have started teaching a part of the curriculum through English, and some located in southeast coastal areas such as Guangdong, Shanghai, and Hong Kong have officially adopted English as their Medium of Instruction (MOI), in an attempt to yield an English-rich earning environment and provide students with opportunities to practice language skills.

However, since English as the medium of instruction imposes high requirements on students' English language proficiency, a significant number of students spend more time learning English to meet high requirements. Additionally, in the context of globalization of goods and services, college students in Putonghua as the MOI programs also try to improve their English skills to enhance their career prospects on the global market. Thanks to the computer and internet technology, E-learning platforms offering English classes taught by native speakers are readily available to students regardless of their geographical locations and consequently have enjoyed a surge in popularity.

This paper aims at finding the differences between two groups of Chinese college students' attitudes when they use E-learning services learning English. Group ONE: 5 students with English as their MOI. Group TWO: 5 mainland students using Putonghua as the MOI. Individual interviews are conducted to collect data, and Grounded Theory is used to analyze the data.

\section{PARTICIPANTS}

Our participants are 10 college students, 5 from English as MOI master programs at the University of Hong Kong (HKU) and the City University of Hong Kong (City U), and 5 from Putonghua MOI master programs offered at three universities located at the northwest area of China mainland, namely Xi'an University of Architecture and Technology (XAUAT), Northwest Normal University (NNU) and Xi'an International Studies University (XISU). 


\section{LANGUAGE BACKGROUND FACTORS ANALYSIS BASED ON GROUNDED THEORY}

Glaser and Strauss[4] developed the Grounded Theory, and Corbin and Strauss [5][6][7]further refined a process of text data categorizing method for qualitative analysis aiming at establishing substantial theory from a large amount of information. It is an outstanding representative method of qualitative research benefiting from its theory generation rooting from real data and the scientific operation process [8]. This study collected and analyzed data according to the classical steps of Grounded Theory: open coding, axial coding, and selective coding.

\subsection{Open Coding}

Open coding is "a process aimed at identifying concepts or key ideas that are hidden with textual data, which are potentially related to the phenomenon of interest"[6] [9]. The obtained text data is conceptually regrouped, and subsequently, similar concepts are grouped into the same categories. Specific steps are: (1) Reading each interview material carefully and analyzing the information line by line to find coding concepts and then classifying the frequently repeated or related concepts under the specific categories.
(2) Grouping the remaining contents into appeared categories or build new nodes if necessary[10]. Since this study explores the different user attitudes between two groups of students, the concepts and subcategories are divided into two groups, respectively, as shown in Table 1 and Table 2(The number in the parentheses indicates the quantity of free nodes.).

\subsection{Axial Coding}

Following the theoretical framework of paper [5], this study compares the whole obtained concepts and subcategories repeatedly and then applies the classical model of axial coding to analyze which categories represent conditions, actions/interactions, and the consequences. Conditions mean the situation or the cause of the phenomenon; actions/interactions point that the strategies for this situation or the results of the interactions; consequences present the results caused by a series preconditions, which may become a new condition of next step. For example, the four subcategories viz English MOI, methods of improving English, using E-learning platforms, and usage frequency, can be integrated into a classical model of axial coding shown in Figure 1.

Table 1 Concepts and categories of group one

\begin{tabular}{|c|c|c|}
\hline No. & subcategories & concepts \\
\hline 1 & English MOI & learn subject-specific terms (2); improve English skills (9); \\
\hline 2 & learning motivation & intrinsic motivation (4); extrinsic motivation (1) \\
\hline 3 & $\begin{array}{l}\text { methods of improving } \\
\text { English }\end{array}$ & Learn by myself (2); speak to native speakers (2) \\
\hline 4 & $\begin{array}{l}\text { Using E-learning } \\
\text { platforms }\end{array}$ & $\begin{array}{l}\text { reading English materials on the internet (3); listening to English } \\
\text { on the internet (2); participating in online English class (2); } \\
\text { watching English movies or TVs (2); record some classes in } \\
\text { English and review them (4) }\end{array}$ \\
\hline 5 & usage frequency & every week (2); every day (3) \\
\hline 6 & perceived ease of use & easy to find what I want (5); obstacle elimination (5) \\
\hline 7 & cost tolerance & prefer free courses (4); will pay if necessary (2) \\
\hline 8 & perceived usefulness & matching users' requirements (4); helpful for my study (3) \\
\hline 9 & share in social network & will share at Wechat (5); friends have shared (5) \\
\hline 10 & providing suggestions & too many advertisements (3); improve the quality of courses (2) \\
\hline
\end{tabular}

Table 2. Concepts and categories of group two

\begin{tabular}{|c|c|c|}
\hline No. & subcategories & concepts \\
\hline 1 & Putonghua MOI & no English environment (4); dumb English (3) \\
\hline 2 & learning motivation & intrinsic motivation (1); extrinsic motivation (5) \\
\hline
\end{tabular}




\begin{tabular}{|c|c|c|}
\hline 3 & methods of learning English & $\begin{array}{c}\text { do English readings (5); remember vocabulary (5); academic } \\
\text { writing (2) }\end{array}$ \\
\hline 4 & Using E-learning platforms & Listening to English on the internet (3) \\
\hline 5 & usage frequency & every week (4) \\
\hline 6 & perceived ease of use & easy to find what I want (5); obstacle elimination (3) \\
\hline 7 & cost tolerance & prefer free courses (5); will pay if necessary (2) \\
\hline 8 & perceived usefulness & matching users' requirements (5); helpful for my study (5) \\
\hline 9 & share in social network & friends have shared (4) \\
\hline 10 & providing suggestions & be free (4); improve the quality of course video (3) \\
\hline
\end{tabular}

\begin{tabular}{|c|c|c|}
\hline Condition & Actions/ interactions. & Consequences- \\
\hline English MOL. & $\begin{array}{c}\text { Methods of improving } \\
\text { English- }\end{array}$ & $\begin{array}{c}\text { Using E-learning } \\
\text { platforms; Usage } \\
\text { frequency. }\end{array}$ \\
\hline
\end{tabular}

Figure 1 Classical model 1 of axial coding

Most students in Group ONE (English as MOI students) have sufficient intrinsic motivation to perform English listening, speaking, reading, and writing, which leads to corresponding actions such as learning or practicing English with native speakers or in other ways. Consequently, the majority of students in this group apply E-learning platforms to improve their English skills in full measure. Hence, high usage frequency in this group is observed (3 out 5 five students use E-learning services daily), and all of them deem that the E-learning applications/websites are easy to use. The whole process aims at improving college students' language skills to cater to the English teaching environment and is therefore labeled the main category of Catering to the English Environment (CEE).
Having enjoyed the convenience and usefulness of both free and paid courses offered by E-learning services, some students in Group ONE with high social characteristics are likely to share the experiences with their friends on social networks, which may, in turn, attract more potential users. Besides, behaviors performed by students in Group ONE, such as offering suggestions to service providers in the hope of modifications tailored to their learning requirements, also help with maintaining a high usage frequency. It is also reported that when the participants encountered issues when using the E-learning platforms, they submitted feedbacks to the platforms and continues using them. We call this process Using Attitude. Based on the analysis above, the causal relationship is shown in Figure 2.

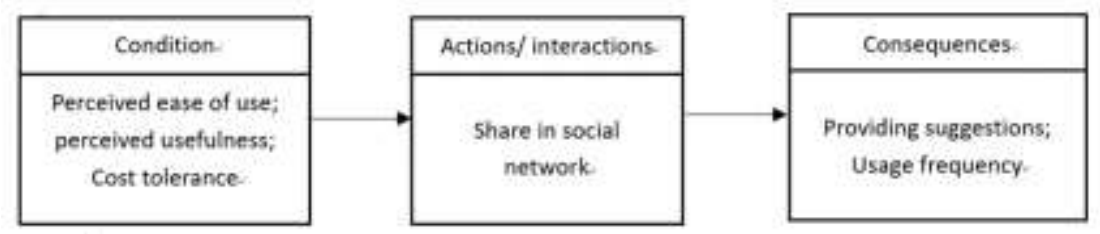

Figure 2 Classical model 2 of axial coding

Similar to Group ONE, Group TWO has two several axial coding processes. Finally, all subcategories are integrated into 6 categories as below (Table 3 ).

Table 3 Main categories from axial coding

\begin{tabular}{|l|c|c|c|c|}
\hline \multicolumn{4}{|c|}{ Group ONE (English MOI) } \\
\hline categories & \multicolumn{3}{|c|}{ Concepts and subcategories } & \multicolumn{2}{c|}{ relationship } \\
\hline & conditions & actions/interactions & consequences & \\
\hline
\end{tabular}




\begin{tabular}{|c|c|c|c|c|}
\hline $\begin{array}{l}\text { Catering to the } \\
\text { English } \\
\text { Environment }\end{array}$ & English MOI & $\begin{array}{c}\text { Methods of improving } \\
\text { English }\end{array}$ & $\begin{array}{l}\text { Using E-learning } \\
\text { platforms; Usage } \\
\text { frequency }\end{array}$ & $\begin{array}{c}\text { Students under the English } \\
\text { environment want to improve } \\
\text { English, which leads to corresponding } \\
\text { language learning behavior. }\end{array}$ \\
\hline $\begin{array}{c}\text { Intrinsic /Extrinsic } \\
\text { Motivation }\end{array}$ & $\begin{array}{l}\text { Learning } \\
\text { motivation }\end{array}$ & $\begin{array}{l}\text { Methods of improving } \\
\text { English; Using E-learning } \\
\text { platforms }\end{array}$ & $\begin{array}{l}\text { Usage frequency; } \\
\text { perceived ease of } \\
\text { use }\end{array}$ & $\begin{array}{l}\text { College students have intrinsic and } \\
\text { extrinsic motivation to learn English } \\
\text { well, so they apply different ways to } \\
\text { learn, including E-learning. As a } \\
\text { result, they feel the convenience of } \\
\text { E-learning and continue to use it. }\end{array}$ \\
\hline Using Experience & $\begin{array}{l}\text { Perceived ease } \\
\text { of use; } \\
\text { perceived } \\
\text { usefulness; Cost } \\
\text { tolerance }\end{array}$ & Share in social network & $\begin{array}{l}\text { providing } \\
\text { suggestions; Usage } \\
\text { frequency }\end{array}$ & $\begin{array}{l}\text { When students feel the convenience } \\
\text { and usefulness of E-learning } \\
\text { platforms, they have the willingness } \\
\text { to share with others. Although they } \\
\text { also propose some suggestions to } \\
\text { suppliers, which do not affect they } \\
\text { continue to use. }\end{array}$ \\
\hline \multicolumn{5}{|c|}{ Group TWO (Putonghua MOI) } \\
\hline \multirow[t]{2}{*}{ categories } & \multicolumn{3}{|c|}{ Concepts and subcategories } & relationship \\
\hline & conditions & actions/interactions & consequences & \\
\hline $\begin{array}{l}\text { Language } \\
\text { environment } \\
\text { impact }\end{array}$ & Putonghua MOI & $\begin{array}{l}\text { Learning motivation; } \\
\text { Methods of improving } \\
\text { English; Using E-learning } \\
\text { platforms }\end{array}$ & Usage frequency & $\begin{array}{c}\text { Students with Putonghua MOI have } \\
\text { fewer opportunities to use English, } \\
\text { but they have a strong willingness to } \\
\text { learn English well pushed by extrinsic } \\
\text { motivation (the international } \\
\text { backgrounds in developing China). } \\
\text { Therefore, they start to improve their } \\
\text { language skills in different ways, } \\
\text { including using E-learning services. } \\
\text { After that, their usage frequency is } \\
\text { likely to increase. }\end{array}$ \\
\hline $\begin{array}{l}\text { External factors } \\
\text { impact }\end{array}$ & $\begin{array}{l}\text { cost tolerance; } \\
\text { Share in social } \\
\text { network }\end{array}$ & Using E-learning platforms & $\begin{array}{l}\text { Perceived ease of } \\
\text { use; perceived } \\
\text { usefulness }\end{array}$ & $\begin{array}{l}\text { Free courses and friends' learning } \\
\text { experiences shared in social networks } \\
\text { attract college students to try } \\
\text { E-learning services. After using, they } \\
\text { perceive the convenience and } \\
\text { usefulness of E-learning products. }\end{array}$ \\
\hline Using Behavioral & $\begin{array}{l}\text { Perceived ease } \\
\text { of use; } \\
\text { perceived } \\
\text { usefulness }\end{array}$ & NA & $\begin{array}{l}\text { Providing } \\
\text { suggestions; Usage } \\
\text { frequency }\end{array}$ & $\begin{array}{l}\text { When students feel the convenience } \\
\text { and usefulness of E-learning services, } \\
\text { they are willing to share user } \\
\text { experiences with friends. } \\
\text { Consequently, their usage frequency } \\
\text { can increase and they also propose } \\
\text { suggestions for service providers to } \\
\text { improve the quality of services. }\end{array}$ \\
\hline
\end{tabular}

\subsection{Selective Coding}

Selective coding involves "identifying a central category or a core variable and systematically and logically relating this central category to other categories" [6][9]. The main tasks of this process include identifying core categories that can guide other categories and then use all materials and relationships developed by them to explain all the phenomena. That is storyline exploration. Through comparing, revising, and searching for logical connections between concepts and categories continuously, this study finds that all the categories found from the interview data can be divided into three groups: Learning Motivation (LM), Environmental Impacts (EI), and Using Attitude (UA).

For Group ONE, all categories are regrouped into LM and UA. LM includes Catering to the English Environment (CEE) and Intrinsic / Extrinsic Motivation (I/EM). In addition, Using Experiences (UE) is included in UA. Because of CEE and I/EM, college students have enough 
motivation to learn English well. Thanks to LM, students learn English by adopting the E-learning approach. That is to say: LM can influence students' UA towards E-learning. This study tries to find a higher order category that subsumes the previously coded category as the core one. Surprisingly, Positive Feedback (PF) is found to be a core bridge from UA to LM. If the users feel satisfied with E-learning services, PF will be generated and then affect LM. PF will stimulate students' learning motivations to make more significant achievements. Conversely, if they feel the products are not to their standard, PF will not be generated. Hence, Positive Feedback is treated as an effective strategy to form positive incentives that guide students to improve intrinsic learning motivation and continue to study. The graphic relationship is shown in Figure 3(The dotted lines indicate the effect of the core category.).

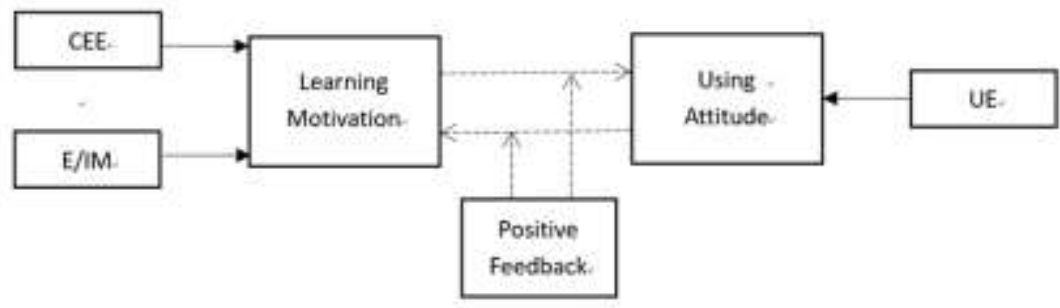

Figure 3 Graphic relationship of group one

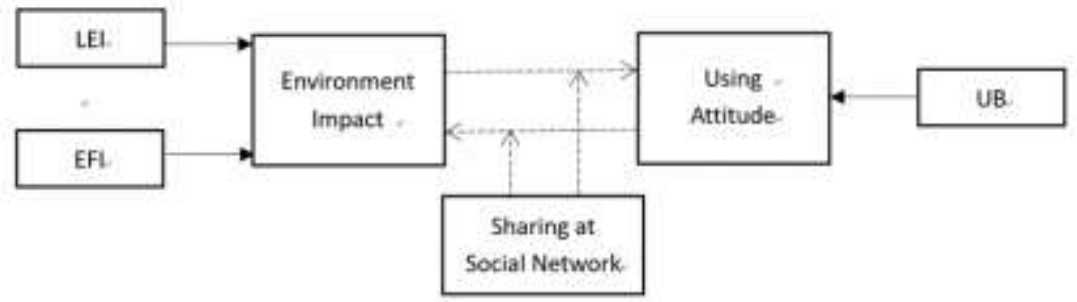

Figure 4 Graphic relationship of group two

In terms of Group TWO, all categories can be grouped into Environmental Impacts (EI) or Using Attitude (UA), with Language Environment Impact (LEI) and External Factors Impact (EFI) belonging to EI and Using Behavioral (UB) belonging to UA. In the context of globalization, English would inevitably play a vital role in higher education examination and career opportunities, which build the extrinsic motivations to push college students to learn the language. It should be noted that this phenomenon has left students in Putonghua as the MOI programs fewer opportunities to use English in their daily life, and as a result, they have no other choices but to seek alternative means to learn English effectively. E-learning emerges and popularizes among students due to its low cost, high efficiency, and user-friendliness. The positive user experience shared on social networks is likely to attract more potential users. Hence, EI can affect students' UB significantly. Simultaneously, the new users' sharing behaviors also guide more potential users to participate in E-learning, which establishes a virtuous cycle. Based on the above, Sharing at Social Network (SSN) is a critical bridge connecting EI and UA, and thus SSN is treated as the core category in Group TWO. The graphic relationship is illustrated below (Figure 4).

\subsection{Theoretical Saturation Testing}

Theoretical saturation is reached when "additional data does not yield any marginal change in the core categories or the relationships" [6] [8]. Theoretical saturation of the above conclusions is tested to ensure the reliability of the study. By coding and analyzing the remaining data, we do not find new concepts, categories, or relationships. Therefore, these two graphic relationships are tested saturated.

\section{RESULTS \& DISCUSSION}

In light of Grounded Theory, this study explores different factors influencing language learning attitude between two groups of college students.

For Group ONE, Learning Motivation (LM), including Catering to the English Environment (CEE) and Intrinsic / Extrinsic Motivation (I/EM), influences students' Using Attitude (UA). Students study in the English MOI programs are entitled to opportunities to learn subject-specific vocabulary in English as well as improve language skills, which contributes to their extrinsic motivation. Simultaneously, students' intrinsic motivation roots from their eagerness to communicate with teachers and peers in 
class using English. Both extrinsic and intrinsic motivation can promote students to learn English. E-learning, being one of the ways of learning English that is characterized by its convenience, low cost, and usefulness, helps students improve their language skills. Meanwhile, good feedback produces positive motivation that encourages students to generate more learning behaviors at online platforms. That is to say, Positive Feedback (PF) emerges as a catalyst accelerating the virtuous cycle between LM and UA. The theoretical model is shown in Figure 5.

In terms of Group TWO, students studying at Putonghua MOI universities almost have no English environment and always study "dumb English" which means they can read and understand English as a second language but cannot speak it. Besides, with the trend of internationlization, English skill establishes a robust competitive advantage when it comes to higher-education opportunities and job hunting. Therefore, the majority of students are pushed by environmental factors and other extrinsic motivation to improve their English skills to the highest degree. Although lots of students still apply traditional ways to learn English, a group of them seeking novelty would like to try English courses offered by E-learning platforms and share their experience on social networks, which attracts more students to join in online classes. In this way, an increasing number of young adults get involved in this new trend of English E-learning services to learn language, and the sharing behave increases rapidly among college students. The whole process becomes a virtuous cycle benefiting from the bridge category labeled Sharing at Social Network (SSN). Therefore, SSN is treated as the core factor influencing students' using attitude towards E-learning platforms in Group TWO. According to the above analysis, the theoretical model of Group TWO can be demonstrated in Figure 6.

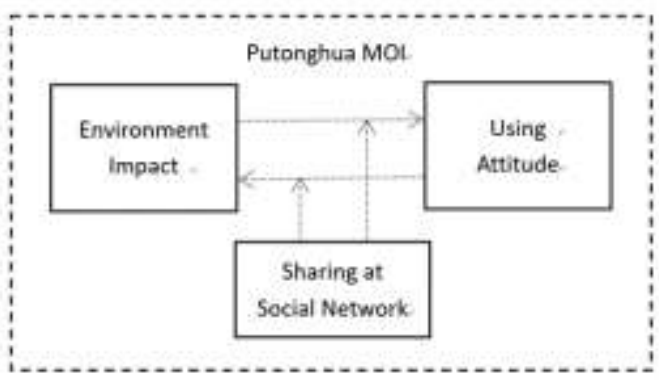

Figure 5. Theory model of English MOI

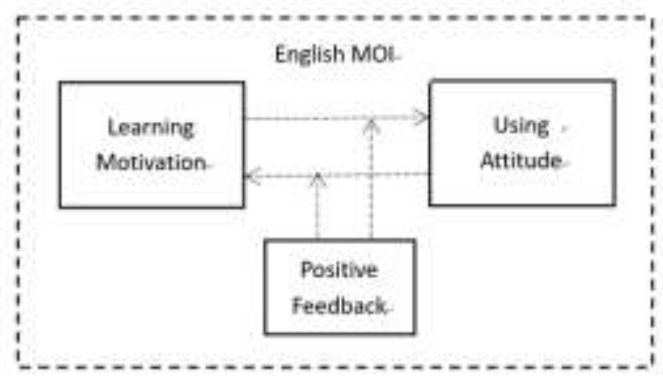

Figure 6 Theory model of Putonghua MOI

\section{FINDINGS \& IMPLICATIONS}

This article aims to explore different user attitudes towards E-learning platforms between two groups of Chinese college students. Employing Ground Theory, we reach the following conclusions:

Students in different language backgrounds (English and Putonghua) exhibit different motivations for E-learning services. In Group ONE, Intrinsic Motivation (IM) is the dominating factor influencing students' Using Attitude (UA), and the Extrinsic Motivation (EM) closely follows These two factors constitute Learning Motivation (LM) as an essential variable directly affecting users' UA. Conversely, regarding Group TWO, most students only have Extrinsic Motivation (EM) pushing them to learn English, and thus the main influencing factor is labeled Environment Impact (EI). That is to say, Intrinsic Motivation (IM) can help students in English MOI programs enhance language learning passion from the inner mind, but under Putonghua MOI, this phenomenon is less observed.

The moderators in these two theory models are different. For Group ONE, Positive Feedback (PF) is the catalyst accelerating the virtuous cycle between LM and UA. Good feedback, such as users' English skill improvement, promotes students' using frequency automatically. Meanwhile, PF towards E-learning services can help service providers improve their quality of service, which may attract more users. In terms of Group TWO, the impact of the external environment accounts for a large proportion. Hence the Sharing at Social Network (SSN) serves as the bridge between Environmental Impact (EI) and Using Attitude (UA). In general, the individual's willingness to use new technology is likely to be influenced by peers' attitudes. Extrinsic factors first push students who use E-learning services. Then some of them share their user experience on social networks, which may attract more potential users (friends or classmates) to join. Students would like to share the user experience means that they approbate its advantages, which helps increase the frequency of using E-learning platforms. To conclude, this study suggests that E-learning service providers should take advantage of this kind of students' social characteristics to attract more college students to participate in E-learning classes.

\section{ACKNOWLEDGMENT}

This work was supported by a grant from the specialized scientific research project "A study on the application status and enhancement strategies of online teaching platforms in private universities in Shaanxi province" of the Education Department of Shaanxi Provincial Government (No. 19JK0677) and the higher education scientific research project "Impact factors and guiding strategies for undergraduate 
employment and further education

decision-making in private universities in

Shaanxi province" of Shaanxi Association of Higher Education (No. XGH19232).

\section{REFERENCES}

[1] Bhuasiri, W., Xaymoungkhoun, O., Zo, H., Rho, J. J., \& Ciganek, A. P. (2012). Critical success factors for e-learning in developing countries: A comparative analysis between ICT experts and faculty. Computers \& Education, 58(2), 843-855.

[2] Ramazani, M., Aghajani, M., Alipanahi, F., \& Sobouti, H. (2013). Effective factors in e-learning acceptance by english language students. Journal of Emerging Trends in Computing and Information Sciences, 4(4).

[3] Mohammadi, N., Ghorbani, V., \& Hamidi, F. (2011). Effects of e-learning on language learning. Procedia Computer Science, 3, 464-468.

[4] Glaser, B., \& Strauss, A. (1967). The discovery of grounded theory. 1967. Weidenfield \& Nicolson, London, 1-19.

[5] Corbin, J. M., \& Strauss, A. (1990). Grounded theory research: Procedures, canons, and evaluative criteria. Qualitative sociology, 13(1), 3-21.

[6] Strauss, A. C., \& Corbin, J. (1998). J: Basics of qualitative research; techniques and procedures for developing grounded theory. Thounsand Oaks: Sage Publications.

[7] Corbin, J., \& Strauss, A. (2003). Grounded theory research: Procedures, canons, and evaluative criteria. Interviewing, 4, 107-124.

[8] Dunne, C. (2011). The place of the literature review in grounded theory research. International journal of social research methodology, 14(2), 111-124.

[9] Bhattacherjee, A. (2012). Social science research: Principles, methods, and practices.

[10] Dougherty, D. (2017). Grounded theory research methods. The Blackwell companion to organizations, 849-866. 